\title{
EDITORIAL
}

\section{Reasons for Rejection}

'Why has it taken so long to reject my paper?' - One of the more difficult tasks that I have to undertake as Chairman of the Editorial Board is drafting the rejection letter to an author. This is not because of the anticipation of having to deal with the irate riposte from the author, nor because rejecting a paper is not the ideal way of maintaining personal relationships with authors who may be friends or former colleagues. Nor is it because of having to make a decision, but rather because I am reminded of a friend who toyed with the idea of putting the quotation 'Judge not that ye be judged' at the beginning of his $\mathrm{PhD}$ thesis. My principal concern is that the author considered the paper worth publishing and I am anxious, when rejecting a paper, in case we have missed the point of the paper and have joined the ranks of editors who have turned down a seminal paper. This is, I believe, why it may take longer to reject a paper than to accept one.

These thoughts led me to analyse the reasons why a paper is rejected and I hope this analysis will form a framework against which I can work.

Some papers submitted to the Journal one can immediately judge as unacceptable. These are papers which really are more suitable for another journal because their subject matter is only of marginal relevance to the nutritional sciences. The papers may be, and often are, sound experimentally and well-prepared; they are, however, not for the British Journal of Nutrition. This judgement may appear subjective, but the decision may well be in the best interests of the author because the paper will be picked-up more quickly in the more appropriate journal. The $B J N$ must also stick to its raison d'etre and clearly cannot publish a paper merely because it is sound.

Occasionally a paper that is marginally relevant is submitted and one has the feeling that it was prepared initially for another journal, whose editor thought that the paper was more appropriate for a nutritional journal. I would hope that an author in this position would have sufficient confidence in the objectivity of the $B J N$ to tell us when this has happened so that we can avoid some fruitless correspondence.

Some papers on an appropriate topic are also clearly unacceptable at the first read; the material is too slight to consider or the design of the study reported is poor. Strict adherence to the Directions to Contributors, while highly desirable if the paper is to be processed rapidly, is only rarely a reason for rejection at this stage. The members of the editorial board, both scientific and statistical, will go to great lengths to help authors when they believe that the material is scientifically interesting and appropriate to the journal.

Recommendations for rejection from referees and members of the editorial board are most frequently made because the design of the study is inappropriate to test the hypothesis that is being raised, or the hypothesis is incompatible with existing evidence. This links back to a previous editorial where I stressed the importance of authors enunciating why the work was undertaken and the central hypothesis being tested. A poor design to a study can be a fatal flaw which is virtually impossible to correct without further experimental work. Occasionally a statistical editor can suggest a remedy but I think that this must be viewed as second best.

The next most common reason for non-acceptance is that the experimental evidence does not support the author's interpretation and alternative interpretations are equally valid. This type of comment often calls for a debate with the authors who, I must say, sometimes 
welcome the new insight that the editor has been able to bring to the data. The scientific editor may decide that the author's position in the debate is not sustainable and recommend rejection at this stage, but I take the view that an author is entitled to his or her own opinion and, since the author is responsible for what will be published under his or her name, I would, in many cases, be prepared to accept a well-argued counter position.

There is of course the converse of this type of rejection 'it's not true', namely 'it's not new', which applies when the editorial board member does not believe that the paper presents new, that is, original research findings. Such a paper may be one of a series, each reporting a small step forward. The paper may be sound but the scientific advance is too small to justify a full paper or, in the worst case, may repeat work previously published elsewhere.

Very rarely a paper is submitted which we are unhappy with for more sinister reasons. It is extremely difficult to spot a well-prepared fabricated paper. The most common clue is that the experimental data 'look too good to be true'. Drafting the rejection letter in this case is very difficult and I am personally pleased that it is very rarely required.

The major reasons for rejection do, I think, raise some cause for concern. The design issue is a very fundamental one and in the eight months that I have been Editor, there have been several papers where the design of major pieces of experimental work was the fatal flaw and the reason for rejection.

This points to a need for much more thought at the inception of a study, and a clear conceptual framework for the hypothesis that is being examined. David Fraser, formerly at the Dunn Nutritional Laboratory, thought that nutritional experiments were too easy to set up and that we as nutritional scientists need to be more diligent in planning.

Finally, an Editor has a pragmatic limit to the number of papers that can be published because of the financial constraints of the costs of publishing. I do not want to reject scientifically-sound papers that fulfil the aims of the British Journal of Nutrition and this will mean that I will have to be very strict with authors regarding the lengths of the papers they submit.

D. A. T. Southgate 